\title{
Dynamic Analysis of Verbal Aggressiveness Networks in School
}

\author{
Dimitrios Theocharis, Alexandra Bekiari \\ Department of Physical Education and Sports, University of Thessaly, Trikala, Greece \\ Email: theoj2009@gmail.com, sandrab@pe.uth.gr
}

How to cite this paper: Theocharis, D. and Bekiari, A. (2018) Dynamic Analysis of Verbal Aggressiveness Networks in School. Open Journal of Social Sciences, 6, 14-28. https://doi.org/10.4236/jss.2018.61002

Received: December 1, 2017

Accepted: January 7, 2018

Published: January 10, 2018

Copyright $\odot 2018$ by authors and Scientific Research Publishing Inc. This work is licensed under the Creative Commons Attribution International License (CC BY 4.0).

http://creativecommons.org/licenses/by/4.0/

\begin{abstract}
Aim of this study is to detect structures of verbal aggressiveness network and also reveal changes through time. Standardized questionnaires have been distributed to 168 students and 8 teachers at secondary schools in 2017. We performed complete social networks analysis and further processing by conventional statistics. According to the results, density could be a first indicator of verbal aggressiveness existence. The verbal aggressiveness seems to become denser through time. Most ties are asymmetric and only a small amount becomes mutual. Thus, inequality appears. Verbal aggressors seem to target more than one victim and use all forms of verbal aggression. Triad analysis can disclose elementary "sources of verbal aggressiveness". More verbal aggression ties are added than deleted over time.
\end{abstract}

\section{Keywords}

Verbal Aggressiveness, Network Analysis, Structure, Dynamic Analysis

\section{Introduction}

Verbal aggressiveness has defined as an attack in the perception of the individual to cause psychological pain to a person's self-concept through communication process [1]. Verbal aggressiveness is considered to be an important but a destructive feature of communication and therefore is worthy of attention in the classroom communication [1]-[11]. Research indicated that verbal aggressiveness affects student-teacher communication [12]-[18], interpersonal attraction [19] [20], Machiavellian tactics [21] [22], bullying [23] [24] and classroom climate [25] [26] [27], students' affective learning [28] [29] [30] [31], discipline reasons [32] [33], fair play behaviours [34] and behaviour, thinking and motivation [26] [35]. Verbal aggressiveness has been examined through network analy- 
sis with similar results [36]-[45].

Purpose of this study is to detect structures of verbal aggressiveness network and to reveal changes through time. The academic added value of this research consists in static and longitude detection and in the exploration of structure of verbal aggressiveness networks. Thereby, a more insightful view is expected to be achieved in the understanding of verbal aggressiveness. To describe the static situation of verbal aggressiveness is descriptive rather than analytical. The diachronic analysis depicts the deeper dynamic of this phenomenon and enables a more sound understanding of constructive or deconstructive tendencies in school socialization. The practical added value consists in using of the results for consulting and pedagogic action in the classes due to the field-specific empirical findings.

\section{Method}

\subsection{Network Analysis}

Complete network analysis emerges a set of methods to study the relations of participants [46] [47]. Network analysis is not based to participants as individuals, but considers the network as an entity, consisting of interacting individuals and measurable relations among them.

The fundamental question in social network analysis is the nature of a dyad. It is the minimal structural element (subgraph) in a social network and shows a probable relationship between two actors [47]. While the study of dyads is a simplest structure of interactions, it is argued that the minimal social group characterized by an interesting level of complexity is a triad. The study of triad's structure informs about transitive actions. Thus, transitivity Model is used to depict [48] used to depict triads.

Several other indicators were used to describe the structure of network like degree, transitivity, reciprocity. Such indicators have been used and interpreted in several empirical researches [22] [49]-[56]. Social network analysis focused on the creation and dissolution of relationships among individual people within a network through different time periods.

\subsection{Sampling}

The survey was conducted at two-time period. The first data set (Wave 1) collected in early fall (October) and the second one (Wave 2) at the late spring (May). The participants were belonging to four classes and the teacher was the one with most teaching hour at the class. Cluster sampling has been used [57] and performed complete network analysis at each class. In this case, the cluster sampling was network sampling (each class was examined as a network).The questionnaires were completed within a class hour (40 minutes). The anonymity of the informants was emphasized and the participation was voluntary.

The sample consisted of 176 individuals. The participants were 168 Greek students ( $47 \%$ boys, $53 \%$ girls) and 8 teachers (50\% men, 50\% women) from 
third grade of a public secondary school (1rst Gymnasium of Trikala). The mean age of students was 14.2 years $(\mathrm{SD}=0.15)$ and the mean age of teachers was 46.5 years $(\mathrm{SD}=1.6)$.

\subsection{Questionnaire}

The participants answered a questionnaire consisted of two parts: a) non-network variables (e.g. gender, times they travel abroad, appearance, etc.), and b) network variables based on the Greek version of Verbal Aggressiveness Scale [58] which consisted of eight items (e.g., "decrease students' self-image", "threats students"). Preliminary examination supported the psychometric properties of the instrument and Confirmatory Factor Analysis indicated satisfactory fit indices (CFI: 0.97, SRMR: 0.02), and internal consistency of the scale $(\alpha=0.96)$.

\subsection{Statistical Analysis}

Visone (version 2.17) was used for the networks' illustration and the computation of several indicators (e.g. node degree, average network degree). Additionally, through visone environment, igraph r-package was used for the computation of additional parameters (e.g. density, reciprocity, transitivity). Also, the visone software was used to depict the alteration of networks over time. Network and non-network data were entered into SPSS 21.0 for further statistical analysis.

\section{Results and Discussion}

\subsection{Structures in Verbal Aggressiveness}

In Table 1 and Table 2, all networks of verbal aggressiveness are depicted. The networks with blue edges represent first wave and the one with red edges the second wave.

Table 1. Depiction of networks A, B (verbal aggressiveness) and their descriptive indicators.

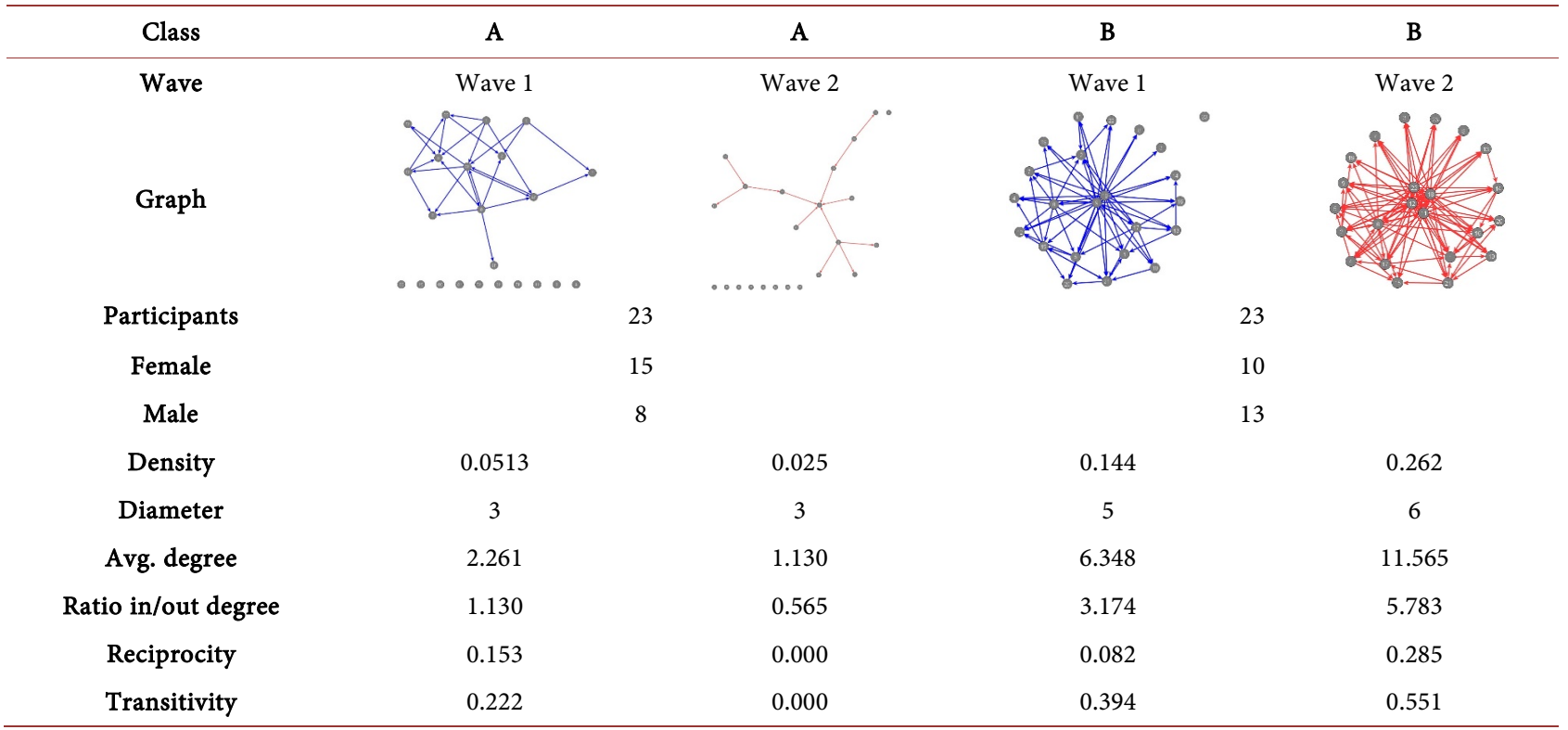


Table 2. Depiction of networks C, D (verbal aggressiveness) and theirs descriptive indicators.

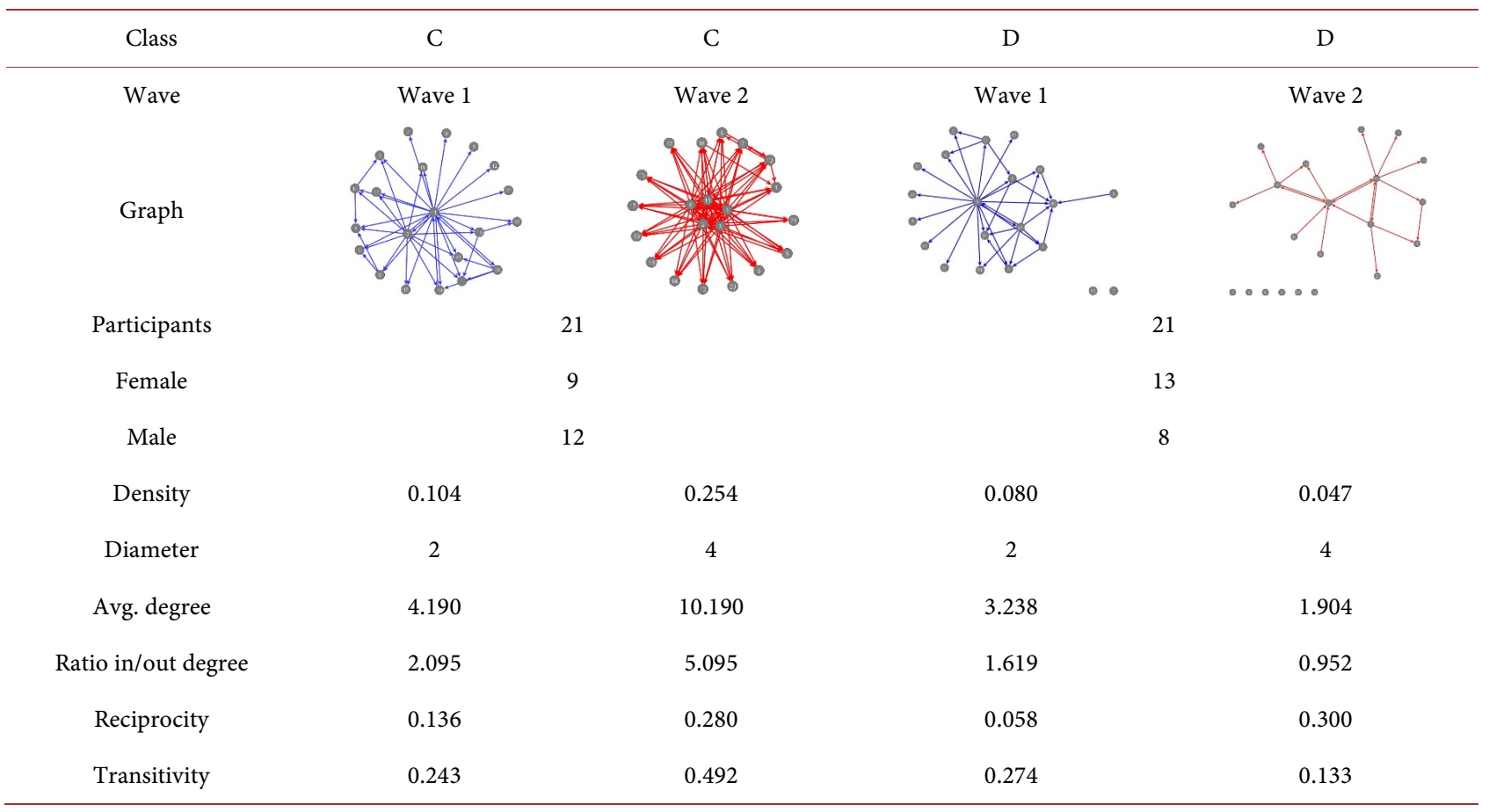

The density varies among networks and seems to be correlated with the average degree of the network, the ratio of in-degree to out-degree and with transitivity. So, the density could be a fist indicator of the existence of verbal aggression with multiple properties. The density of all networks is at low level (below 0.30 ) but networks $A$ and $D$ have the minimum density (below 0.08). Also, the range of reciprocity in networks has been ranged at low level (below 0.30).

\subsection{Degree Correlation}

In Appendix, Spearman correlation of degree is being presented. All items of verbal aggressiveness scale have been correlated at both waves of the research. If someone uses verbal aggressiveness it is likely to practically use all its forms.

Comparing the two phases could be observed that most items also correlate between two waves. Only "mocking behaviour" and partial "lessening behaviour" seem not to be associated. This could be explained by social learning. If someone experienced verbal aggressiveness is in part susceptible not to pay attention to future behaviours, thinking that behaviours are "normal" for the particular person. From an additional point of view, one could distinguish between cohesive core of verbal aggressiveness dimensions and not cohesive ones.

\subsection{Dyads}

In Table 3, the dyad census (MAN) is presented as percentage. The number in the parenthesis depicts the existing dyads. The null relations have the majority of the interactions and represent the absence of verbal aggressiveness. The null dyads are increased in networks $\mathrm{A}$ and $\mathrm{B}$ so the verbal aggressiveness is de- 
creased. On the contrary, at the networks $\mathrm{C}$ and $\mathrm{D}$ null dyads decreased and the verbal aggressiveness increased.

A small amount of the relations is mutual. As expected, only in the networks with high density the mutual dyads have shown high percentage. The majority of existing verbal aggressiveness is asymmetric. It could be explained by the "usual" process of verbal aggressiveness leading to inequality. First someone uses verbal aggressiveness (asymmetric relation) with purpose to hurt somebody. Only if the "victim" similarly reacts, then the relation becomes mutual.

Figure 1 shows the existence of verbal aggressiveness based on the sum of mutual and asymmetric dyads in four classes. Standard error bars are also presented. In networks B and C, verbal aggressiveness increased and at the networks $A$ and D verbal aggressiveness decreased. In the networks $B$ and $C$, there is a strong evidence for verbal aggressiveness proliferation.

\subsection{Change of Verbal Aggressiveness over Time}

The change over time can be depicted in four networks (Table 4 and Table 5). Between the two phases no intervention took place.

Table 3. Dyad census.

\begin{tabular}{ccccccccc}
\hline & A Wave 1 & A Wave 2 & B Wave 1 & B Wave 2 & C Wave 1 & C Wave 2 & D Wave 1 & D Wave 2 \\
\hline Mutual & $0.79 \%(2)$ & $0.00 \%(0)$ & $1.19 \%(3)$ & $7.51 \%(19)$ & $1.43 \%(3)$ & $7.14 \%(15)$ & $0.48 \%(1)$ & $1.43 \%(3)$ \\
Asymmetric & $8.70 \%(22)$ & $5.14 \%(13)$ & $26.48 \%(67)$ & $37.55 \%(95)$ & $18.10 \%(38)$ & $36.67 \%(77)$ & $15.24 \%(32)$ & $6.67 \%(14)$ \\
Null & $90.51 \%(229)$ & $94.86 \%(240)$ & $72.33 \%(183)$ & $54.94 \%(139)$ & $80.48 \%(169)$ & $56.19 \%(118)$ & $84.29 \%(177)$ & $91.90 \%(193)$ \\
\hline
\end{tabular}

\section{$60 \%$}

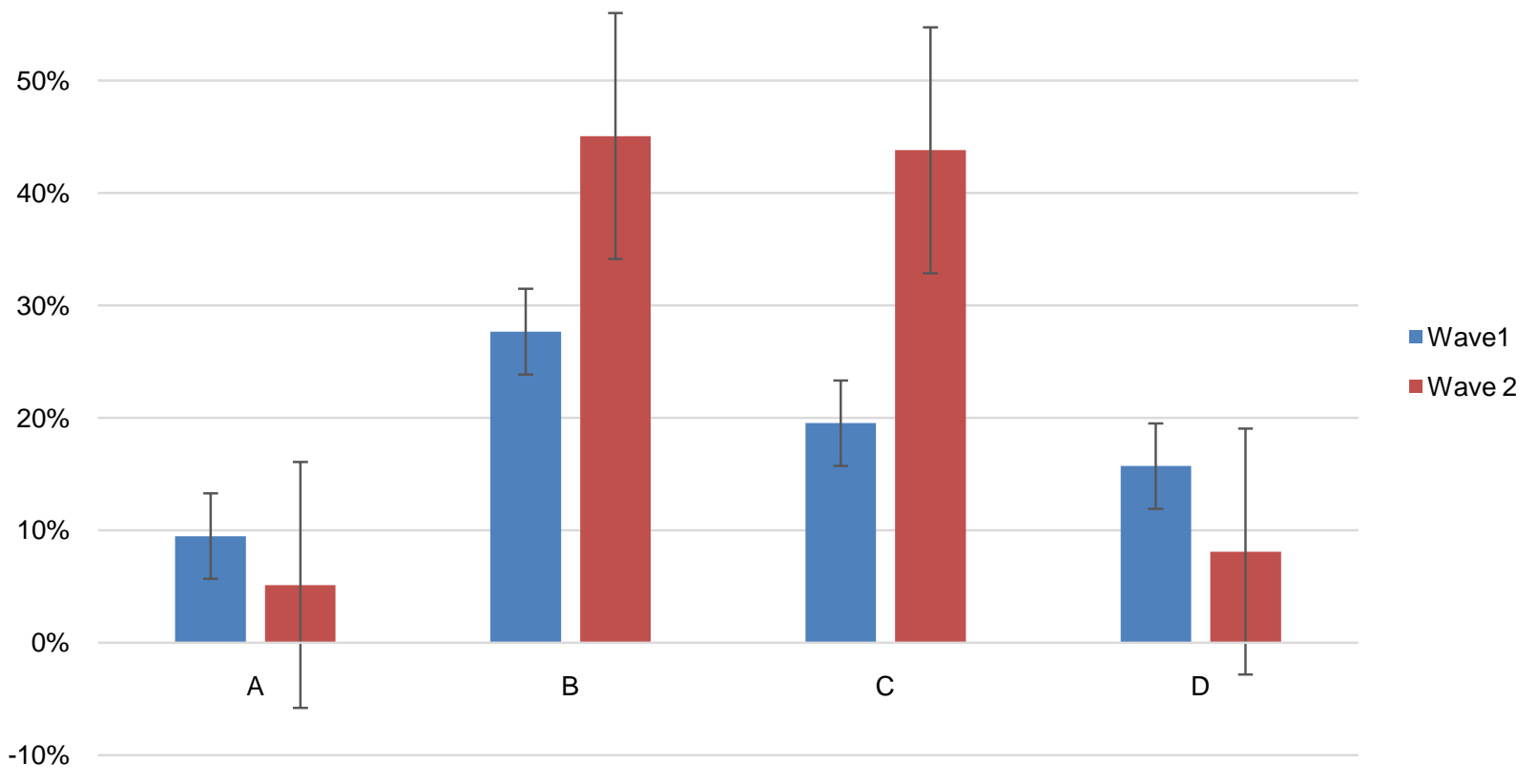

Figure 1. Verbal aggressiveness over time (based on mutual and asymmetric dyads). 
Table 4. Change of verbal aggressiveness network (A and B) over time.

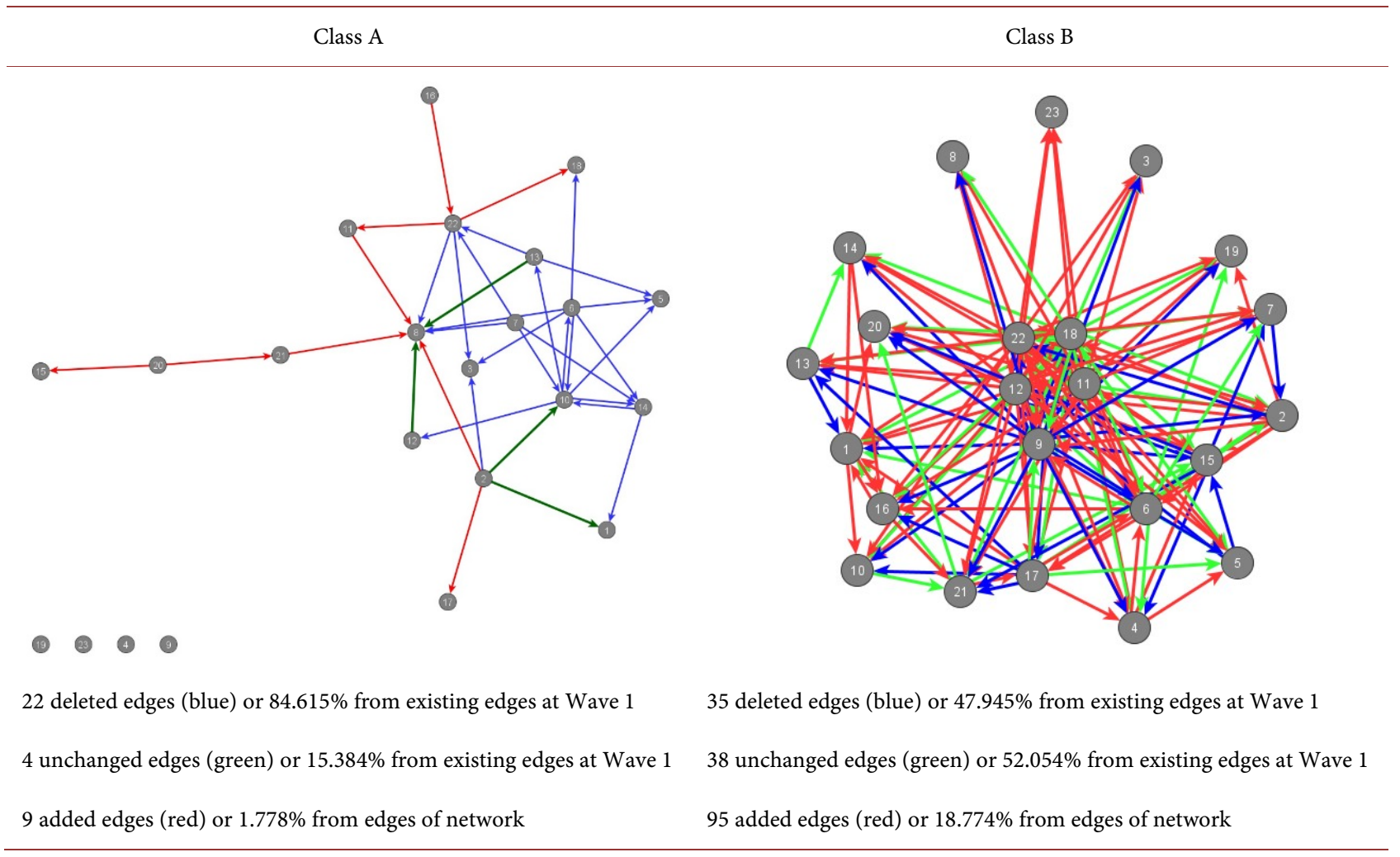

Table 5. Change of verbal aggressiveness network (C and D) over time.

\section{Class C}

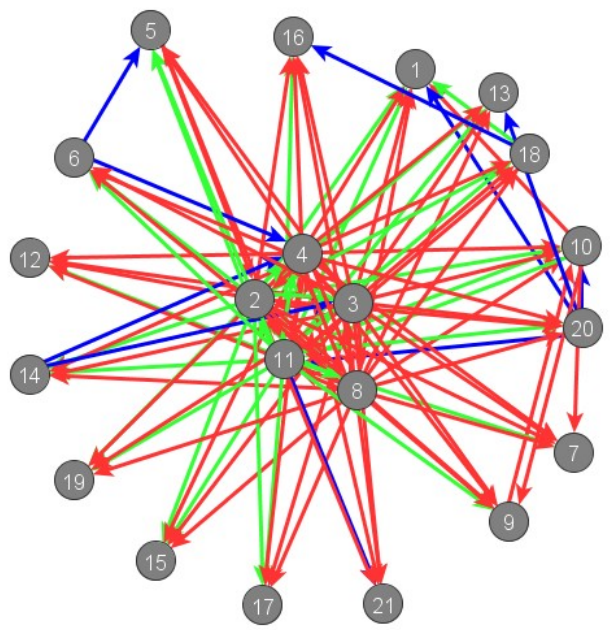

10 deleted edges (blue) or $22.727 \%$ from existing edges at Wave 1

34 unchanged edges (green) or $77.272 \%$ from existing edges at Wave 1

73 added edges (red) or $17.381 \%$ from edges of network
Class D

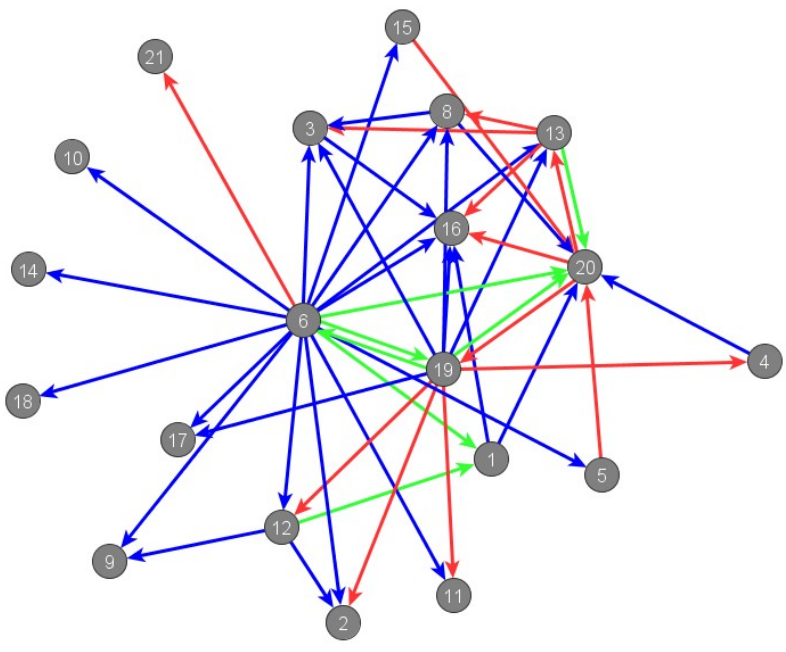

(7)

27 deleted edges (blue) or $79.411 \%$ from existing edges at Wave 1

7 unchanged edges (green) or 20.588\% from existing edges at Wave 1 13 added edges (red) or 3.095\% from edges of network 
In networks $\mathrm{A}$ and $\mathrm{D}$, a large amount of the existing edges have been deleted. Also, little new edges have been added. If we consider the density of classes A and $\mathrm{D}$, we could assume that low level density conserves verbal aggressiveness at low level.

In the other two networks ( $\mathrm{B}$ and $\mathrm{C}$ ) with higher density, the greatest part of existing verbal aggressiveness has been conserved. Also, a large amount of new relations added to the networks. Thus, it is reasonably assumed that the denser is the network the more aggressive becoming over time.

\subsection{Triads}

A triad in a directed graph is a subgraph which is composed of three nodes and the possible relation between them. The triad census is an especially useful summary of asocial network since it makes a large amount of network indicators calculable [48].

In Table 6, all triads of transitivity model [48] is being presented. All values are presented in the percentage form.

In Figure 2, the triad distribution over time is presented. The null triads constitute the majority of the triads in all networks. Except from triad 003 the most common triads are $021 \mathrm{D}, 012,120 \mathrm{U}$, and with lower quantity are the triads $111 \mathrm{U}, 030 \mathrm{~T}, 102$. The other triads have negligible quantity. The four types of the triad $(003,012,102,021 \mathrm{D})$ it is usual to occur in a low-density network [59]. Especially the triads $021 \mathrm{D}$ with higher rankings can be perceived as containing "source of verbal aggressiveness" (a node attacking to the other two). The triads $111 \mathrm{U}, 030 \mathrm{~T}, 120 \mathrm{U}$ similarly contain "sources of verbal aggressiveness". These triads are at higher level when the network is denser.

Figure 3 shows the existence of verbal aggressiveness based on the triads in four classes. Standard error bars are also presented. One can observe similar results to these of dyads. Thus, triads produce no more particular interactive synergy than dyads.

\section{Conclusions}

Verbal aggressiveness is presented in all classes, but the structural features are differentiated. Verbal aggressiveness's network seems to have low density (below $0.5)$. The differences between network's densities could be an indicator of the existence of verbal aggressiveness. A future question for research could be if the density of the verbal aggressiveness is correlated with the gender because the network with lower density has more women than men.

Most relations are asymmetric. There are few mutual aggressive ties. This could show that many students don't choose to respond with the same way, even if they have been attacked verbally. Thus, inequality appears. This behavioural pattern could explain why highly argumentative persons perceive arguing as a mean for lessening conflict.

Triad analysis can disclose elementary "sources of verbal aggressiveness". This 
Table 6. Triads.

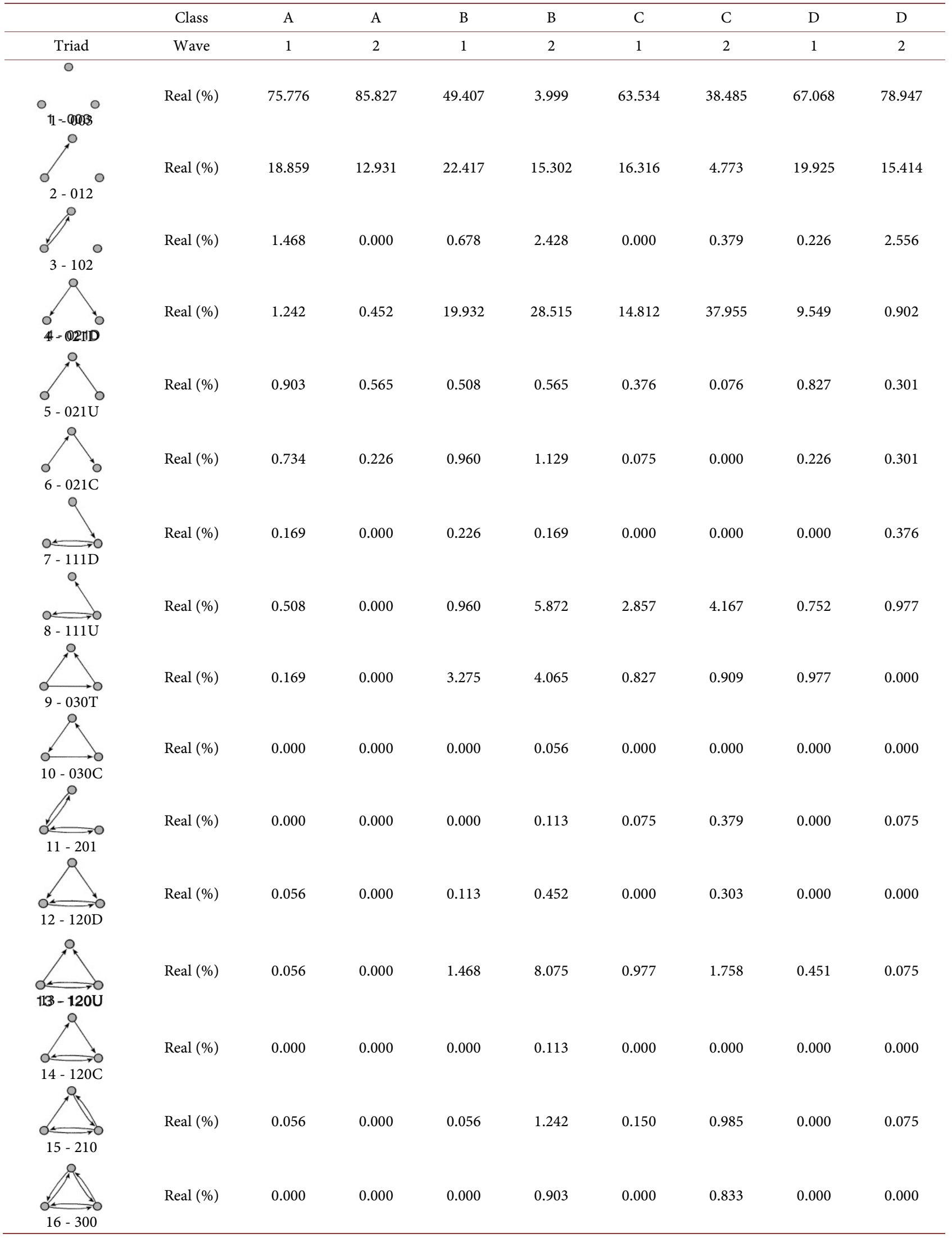




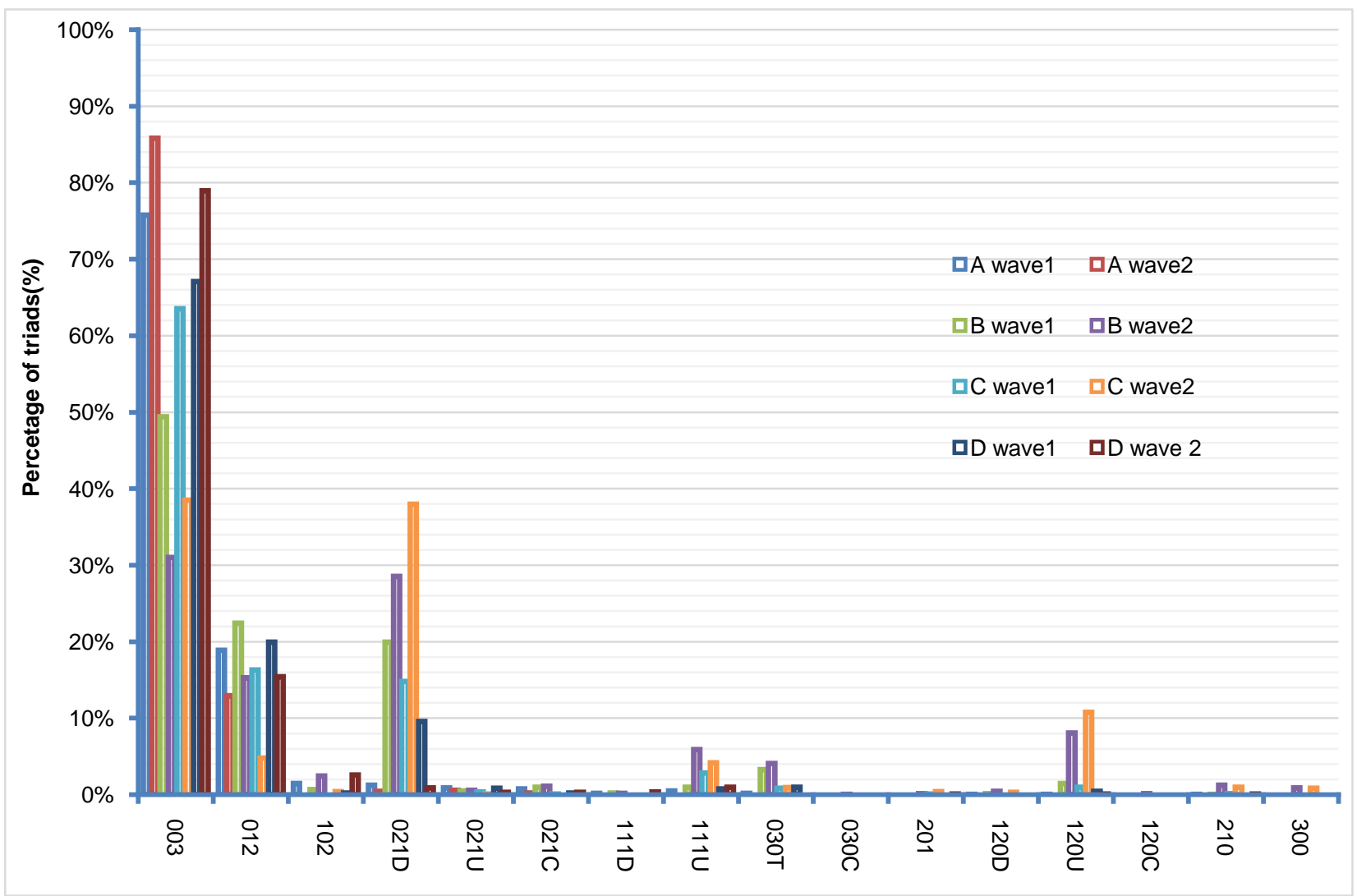

Figure 2. Triad number distribution.

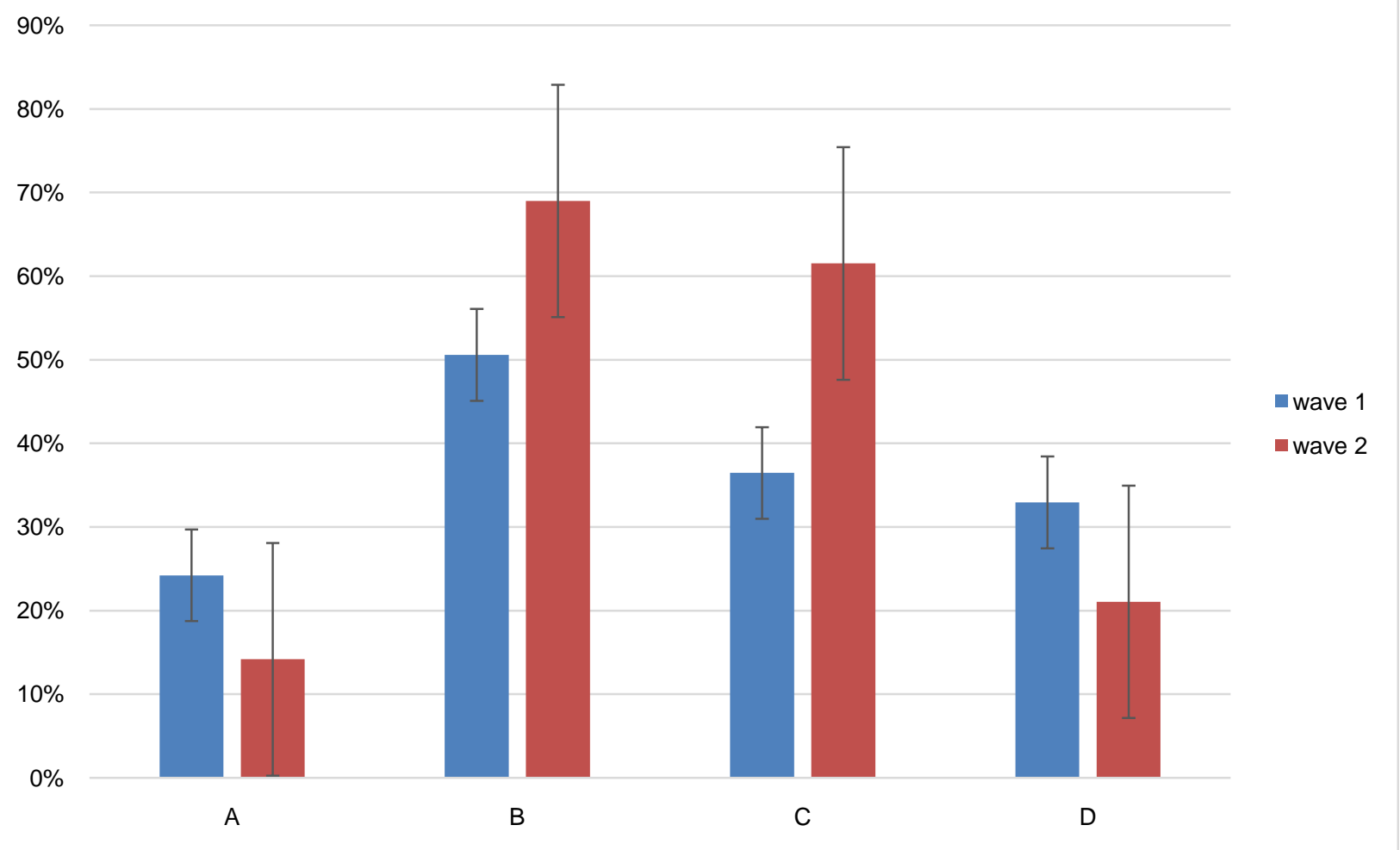

Figure 3. Verbal aggressiveness over time (based on triads). 
can be interpreted that if someone is verbal aggressive, he/she probably will direct it to multiple targets. Also, correlation revealed that verbally aggressive students probably tend to use as many verbal aggressiveness forms as possible to harm the self-concepts of other students. However, one can distinguish between cohesive and not cohesive core of verbal aggressiveness dimensions.

Over time analysis showed the way of proliferation and reduction of verbal aggression. If verbal aggressiveness becomes denser, one can observe a greater amount of new verbal attacks added to the networks and only a small amount of the existing relation deleted. "Violence begets violence". On the contrary, the diminution of the existing verbal aggressiveness without adding new entries seems to decrease verbal aggressiveness.

\section{References}

[1] Infante, D.A. and Wigley, C.J. (1986) Verbal Aggressiveness: An Interpersonal Model and Measure. Communication Monographs, 53, 61-69. http://dx.doi.org/10.1080/03637758609376126

[2] Bekiari, A. (2012) Perceptions of Instructors' Verbal Aggressiveness and Physical Education Students' Affective Learning. Perceptual and Motor Skills, 115, 325-335. http://dx.doi.org/10.2466/06.11.16.PMS.115.4.325-335

[3] Bekiari, A. (2014) Verbal Aggressiveness and Leadership Style of Sports Instructors and Their Relationship with Athletes' Intrinsic Motivation. Creative Education, 5, 114-121. http://dx.doi.org/10.4236/ce.2014.52018

[4] Bekiari, A., Kokaridas, D. and Sakellariou, K. (2005) Verbal Aggressiveness of Physical Education Teachers and Students' Self-Reports of Behaviour. Psychological Reports, 96, 493-498. http://dx.doi.org/10.2466/pr0.96.2.493-498

[5] Bekiari, A., Kokaridas, D. and Sakellariou, K. (2006) Associations of Students' Self-Reports of Their Teacher'S Verbal Aggression, Intrinsic Motivation, and Perceptions of Reasons for Discipline in Greek Physical Education Classes. Psychological Reports, 98, 451-461. http://dx.doi.org/10.2466/PR0.98.2.451-461

[6] Bekiari, A., Koustelios, A. and Sakellariou, K. (2000) Instructors' Verbal Aggressiveness from Universities in Greece. Studi e Ricerche, 5, 225-232.

[7] Bekiari, A. and Manoli, P. (2016) EFL Teacher Verbal Aggressiveness and Argumentativeness and Student Socio-Affective Strategy Use and Affective Learning: Exploring Possible Associations. Journal of Teacher Education and Educators, 5, 154-171.

[8] Bekiari, A., Patsiaouras, A., Kokaridas, D. and Sakellariou, K. (2006) Verbal Aggressiveness and State Anxiety of Volleyball Players and Coaches. Psychological Reports, 99, 630-634. http://dx.doi.org/10.2466/PR0.99.2.630-634

[9] Infante, D.A. (1995) Teaching Students to Understand and Control Verbal Aggression. Communication Education, 44, 51-63. https://doi.org/10.1080/03634529509378997

[10] Myers, S.A., Edwards, C., Wahl, S.T. and Martin, M.M. (2007) The Relationship between Perceived Instructor Aggressive Communication and College Student Involvement. Communication Education, 56, 495-508. http://dx.doi.org/10.1080/03634520701466398

[11] Deliligka, S., Bekiari, A. and Syrmpas, I. (2017) Verbal Aggressiveness and Argumentativeness in Physical Education: Perceptions of Teachers and Students in qUa- 
litative and Quantitative Exploration. Psychology, 8, 1693-1717. https://doi.org/10.4236/psych.2017.811112

[12] Bekiari, A. (2017) Exploring Relations between Instructors' Verbal Aggressiveness and Argumentativeness and Students' Fair Play Behaviours and Machiavellianism. International Journal of Physical Education, 54, 26-39.

[13] Bekiari, A. (2017b) Verbally Aggressive Instructors and Machiavellian Students: Is the Socio-Communicative Style an Over-Bridging? Psychology, 8, 1437-1454. http://dx.doi.org/10.4236/psych.2017.810095

[14] Bekiari, A., Digelidis, N. and Sakellariou, K. (2006) Perceived Verbal Aggressiveness of Coaches in Volleyball and Basketball: A Preliminary Study. Psychological Reports, 103, 526-530. http://dx.doi.org/10.2466/PMS.103.2.526-530

[15] Bekiari, A. and Sakellariou, K. (2003) Perceived Instructor Verbal Aggressiveness and Student State Learning in Physical Education. Italian Journal of Sport Sciences, 1, 251-256.

[16] Bekiari, A. and Balla, K. (2017) Instructors and Students Relations: Argumentativeness, Leadership and Goal Orientations. Open Journal of Social Sciences, 5, 128-143. https://doi.org/10.4236/jss.2017.57009

[17] Buford, A.M. (2010) Perception Becomes Reality: Student-Teacher Relationships and Verbally Aggressive Messages. Master, Cleveland State University, Cleveland.

[18] Rocca, K.A. and McCroskey, J.C. (1999) The Interrelationship of Student Ratings of Instructors' Immediacy, Verbal Aggressiveness, Homophily, and Interpersonal Attraction. Communication Education, 48, 308-316.

https://doi.org/10.1080/03634529909379181

[19] Bekiari, A. and Petanidis, D. (2016) Exploring Teachers' Verbal Aggressiveness through Interpersonal Attraction and Students' Intrinsic Motivation. Open Journal of Social Sciences, 4, 72-85. https://doi.org/10.4236/jss.2016.412007

[20] Syrmpas, I. and Bekiari, A. (2015) The Relationship between Perceived Physical Education Teacher's Verbal Aggressiveness and Argumentativeness with Students' Interpersonal Attraction. Inquiries in Sport \& Physical Education, 13, 21-32.

[21] Bekiari, A. (2016) Insights into Instructors' Verbal Aggressiveness and Students' Machiavellianism through Leadership Style and Motivational Climate. European Scientific Journal, 12, 90-110. https://doi.org/10.19044/esj.2016.v12n25p90

[22] Bekiari, A. and Spanou, K. (2018) Machiavellianism in Universities: Perceiving Exploitation in Student Networks. Social Networking, 7, 19-31. https://doi.org/10.4236/sn.2018.71002

[23] Bekiari, A. and Pachi, V. (2017) Insights into Bullying and Verbal Aggressiveness through Social Network Analysis. Journal of Computer and Communications, 5, 79-101. https://doi.org/10.4236/jcc.2017.59006

[24] Bekiari, A., Pachi, V. and Hasanagas, N. (2017) Investigating Bullying Determinants and Typologies with Social Network Analysis. Journal of Computer and Communications, 5, 11-27. https://doi.org/10.4236/jcc.2017.57002

[25] Bekiari, A. and Syrmpas, I. (2015) Coaches' Verbal Aggressiveness and Motivational Climate as Predictors of Athletes' Satisfaction. British Journal of Education, Society and Behavioural Science, 9, 318-329. https://doi.org/10.9734/BJESBS/2015/17757

[26] Mazer, J.P. and Stowe, S.A. (2015) Can Teacher Immediacy Reduce the Impact of Verbal Aggressiveness? Examining Effects on Student Outcomes and Perceptions of Teacher Credibility. Western Journal of Communication, 80, 1-17.

[27] Myers, S.A. and Rocca, K.A. (2000) The Relationship between Perceived Instructor 
Communicator Style, Argumentativeness, and Verbal Aggressiveness. Communication Research Reports, 17, 1-12. https://doi.org/10.1080/08824090009388745

[28] Bekiari, A. and Tsaggopoulou, T. (2016) Verbal Aggressiveness and Affective Learning in Physical Education. Advances in Physical Education, 6, 406-418. https://doi.org/10.4236/ape.2016.64041

[29] Myers, S.A. and Knox, R.L. (1999) Verbal Aggression in the College Classroom: Perceived Instructor Use and Student Affective Learning. Communication Quarterly, 47, 33-45. https://doi.org/10.1080/01463379909370122

[30] Schrodt, P. (2003) Students' Appraisals of Instructors as a Function of Students' Perceptions of Instructors' Aggressive Communication. Communication Education, 52, 106-121. https://doi.org/10.1080/03634520302468

[31] Wrench, J.S. and Punyanunt-Carter, N.M. (2005) Advisor-Advisee Communication Two: The Influence of Verbal Aggression and Humor Assessment on Advisee Perceptions of Advisor Credibility and Affective Learning. Communication Research Reports, 22, 303-313. https://doi.org/10.1080/000368105000317599

[32] Bekiari, A. and Tsiana, I. (2016) Exploring Instructors' Verbal Aggressiveness and Students' Personal Orientations and Reasons of Discipline in Physical Education Class. Advances in Physical Education, 6, 158-168. https://doi.org/10.4236/ape.2016.63018

[33] Bekiari, A. and Pylarinou, M. (2017) Instructor Argumentativeness and Socio-Communicative Style and Student Discipline: Using Physical Education Students' Class as an Illustration. Open Journal of Social Sciences, 5, 122-136. https://doi.org/10.4236/jss.2017.53011

[34] Hassandra, M., Bekiari, A. and Sakellariou, K. (2007) Physical Education Teacher's Verbal Aggression and Student's Fair Play Behaviors. The Physical Educator, 64, 94-101.

[35] Manoli, P. and Bekiari, A. (2015) EFL Teachers' Verbal Aggressiveness and Students' Intrinsic Motivation and Social-Affective Strategy Use: Investigating Possible Relations. Advances in Research, 5, 1-13. https://doi.org/10.9734/AIR/2015/19692

[36] Bekiari, A., Deliligka, S. and Koustelios, A. (2016) Examining Relations of Aggressive Communication in Social Networks. Social Networking, 6, 38-52. https://doi.org/10.4236/sn.2017.61003

[37] Bekiari, A., Nikolaidou, Z. and Hasanagas, N. (2017) Typology of Motivation and Aggression on the Basis of Social Network Variables: Examples of Complementary and Nested Behavioral Types through Conventional Statistics. Social Networking, 6, 135-147. https://doi.org/10.4236/sn.2017.62008

[38] Bekiari, A. and Hasanagas, N. (2016a) Sociological Insights in the Education System: "Unlocking" the Power Relations. AfoiKyriakidi Editions S.A., Thessaloniki.

[39] Bekiari, A. and Hasanagas, N. (2016b) "Educating" in Physical Education. Theoretical Approaches and Practical Inquiries. AfoiKyriakidi Editions S.A., Thessaloniki.

[40] Bekiari, A. and Hasanagas, N. (2016c) Suggesting Indicators of Superficiality and Purity in Verbal Aggressiveness. An Application in Adult Education Class Networks of Prisoners. Open Journal of Social Sciences, 4, 279-292. https://doi.org/10.4236/jss.2016.43035

[41] Hasanagas, N. and Bekiari, A. (2015) Depicting Determinants and Effects of Intimacy and Verbal Aggressiveness Target through Social Network Analysis. Sociology Mind, 5, 162-175. https://doi.org/10.4236/sm.2015.53015 
[42] Hasanagas, N., Bekiari, A. and Vasilos, P. (2017) Friendliness to Animals and Verbal Aggressiveness to People: Using Prison Inmates Education Networks as an Illustration. Social Networking, 6, 224-238. https://doi.org/10.4236/sn.2017.63015

[43] Theocharis, D. and Bekiari, A. (2016) The Influence of Mathematics and Learning Environment in Verbal Aggressiveness and Interpersonal Relations: A Dynamic Analysis of Social Networks. Proceedings of the 8 th International Congress Mathematical Society, Thessaloniki, 30 March-3 April 2016, 415-428.

[44] Theocharis, D. and Bekiari, A. (2016) Social Networks Analysis of Centrality: Case Study in Leadership Networks. Proceedings of the 33rd Congress Greek Mathematical Society (With International Participation), Chania, 4-6 November 2016, 250-260.

[45] Theocharis, D., Bekiari, A. and Koustelios, A. (2017) Exploration of Determinants of Verbal Aggressiveness and Leadership through Network Analysis and Conventional Statistics. Using School Class as an Illustration. Sociology Mind, 7, 27-43. https://doi.org/10.4236/sm.2017.72003

[46] Scott, J. (2000) Social Network Analysis: A Handbook. Sage, London.

[47] Wasserman, S. and Faust, K. (1994) Social Network Analysis: Methods and Applications. Vol. 8, Cambridge University Press, Cambridge. https://doi.org/10.1017/CBO9780511815478

[48] Holland, P.W. and Leinhardt, S. (1977) A Dynamic Model for Social Networks. Journal of Mathematical Sociology, 5, 5-20. https://doi.org/10.1080/0022250X.1977.9989862

[49] Bekiari, A., Deliligka, S. and Hasanagas, N. (2017) Analysing Networks of Verbal Aggressiveness and Motivation. Psychology, 8, 495-515. https://doi.org/10.4236/psych.2017.83031

[50] Bekiari, A., Hasanagas, N., Theocharis, D., Kefalas, I. and Vasilou, A. (2015) The Role of Mathematical Object and the Educational Environment to Students' Interpersonal Relationships: An Application of Full Social Network Analysis. Proceedings of the 32nd Congress Greek Mathematical Society (With International Participation), Kastoria, 799-812.

[51] Bekiari, A. and Hasanagas, N. (2015) Verbal Aggressiveness Exploration through Complete Social Network Analysis: Using Physical Education Students' Class as an Illustration. International Journal of Social Science Studies, 3, 30-49.

https://doi.org/10.11114/ijsss.v3i3.729

[52] Bekiari, A. and Spyropoulou, S. (2016) Exploration of Verbal Aggressiveness and Interpersonal Attraction through Social Network Analysis: Using University Physical Education Class as an Illustration. Open Journal of Social Sciences, 4, 145-155. https://doi.org/10.4236/jss.2016.46016

[53] Hasanagas, N. and Bekiari, A. (2017) An Exploration of the Relation between Hunting and Aggressiveness: Using Inmates Networks at Prison Secondary School as an Illustration. Social Networking, 6, 19-37. https://doi.org/10.4236/sn.2017.61002

[54] Theocharis, D. and Bekiari, A. (2017) Structural Analysis of Leadership in School Class Networks. Proceedings of the 34nd Congress Greek Mathematical Society ( With International Participation), Lefkada, 3-5 November 2017, 271-279.

[55] Theocharis, D. and Bekiari, A. (2017) Applying Social Network Indicators in the Analysis of Verbal Aggressiveness at the School. Journal of Computer and Communications, 5, 169-181. https://doi.org/10.4236/jcc.2017.57015 
[56] Theocharis, D. and Bekiari, A. (2017) Cumulative Hierarchy Analysis (Katz Centrality) on Leadership Networks of Learning Communities. Proceedings of the 9 th International Congress Mathematical Society, Thessaloniki, 17-19 March 2017, 285-297.

[57] Farmakis, N. (2000) Introduction to Sampling. Christodoulidis, Thessaloniki. (In Greek)

[58] Bekiari, A. and Digelidis, N. (2015) Measuring Verbal Aggressiveness in Sport and Education. International Journal of Physical Education, 4, 12-21.

[59] Zvereva, O.M. (2016) Triad Census Usage for Communication Network Analysis. Paper Presented at the AIST (Supplement). 


\section{Appendix}

Spearman correlation of verbal aggressiveness (degree).

\begin{tabular}{|c|c|c|c|c|c|c|c|c|c|c|c|c|c|c|c|c|}
\hline & 1 & 2 & 3 & 4 & 5 & 6 & 7 & 8 & 9 & 10 & 11 & 12 & 13 & 4 & 15 & 16 \\
\hline \multirow{2}{*}{$\begin{array}{l}\text { 1. insulting } \\
\text { behaviour/wave } 1\end{array}$} & 0 & * & & & 0 & 0 & & & ${ }^{*} 0.386^{* *}$ & 0.083 & $0.259^{*}$ & $0.228^{*}$ & $0.406^{* *}$ & 0.168 & $0.257^{*}$ & \\
\hline & & 0.000 & 0.000 & 0.000 & 0.000 & 0.000 & 0.000 & 0.000 & 0.000 & 0.440 & 0.015 & 0.033 & 0.000 & 0.117 & 0.015 & 0.049 \\
\hline \multirow{2}{*}{$\begin{array}{l}\text { 2. underestimated } \\
\text { attitude/wave } 1\end{array}$} & $704^{* *}$ & 0 & & & & & & & & 0 & & 8 & & & & \\
\hline & 0.000 & . & 0.000 & 0.000 & 0.000 & 0.000 & 0.017 & 0.000 & 0.003 & 0.066 & 0.088 & 0.199 & 0.021 & 0.042 & 0.009 & 0.114 \\
\hline \multirow{2}{*}{$\begin{array}{l}\text { 3. underestimating } \\
\text { intelligence/wave } 1\end{array}$} & $0.545^{* *}$ & $0.563^{* *}$ & 1.000 & $0.458^{* *}$ & $0.386^{* *}$ & $0.487^{* *}$ & $0.349^{* *}$ & 0. & 0 & 0.007 & 0.159 & 0.083 & $5^{*}$ & .131 & 35 & .047 \\
\hline & 0.000 & 0.000 & . & 0.000 & 0.000 & 0.000 & 0.001 & 0.000 & 0.017 & 0.948 & 0.140 & 0.439 & .044 & .223 & .209 & .664 \\
\hline \multirow{2}{*}{$\begin{array}{l}\text { 4. ironic } \\
\text { comments/wave } 1\end{array}$} & & & & 1 & & & & & & 0 & & & & & & \\
\hline & 0.000 & 0.000 & 0.000 & . & 0.000 & 0.000 & 0.000 & 0.000 & 0.001 & 0.869 & 0.028 & 0.008 & 0.002 & 0.029 & 0.001 & 0.087 \\
\hline \multirow{2}{*}{$\begin{array}{l}\text { 5. rude } \\
\text { behaviour/wave } 1\end{array}$} & & & & & 1.000 & 0 & & & & 6 & & & & & 204 & \\
\hline & 0 & 0.000 & 0. & & . & & & & & 1 & & & 3 & & 56 & .174 \\
\hline \multirow{2}{*}{$\begin{array}{l}\text { 6. lessening } \\
\text { behaviour/wave } 1\end{array}$} & & & & 0.5 & $0.518^{* *}$ & 1.000 & $0.247^{*}$ & & & 0.152 & & & 4 & & & \\
\hline & 0.000 & 0.000 & 0.000 & 0.000 & 0.000 & & 0.021 & 0. & 0.033 & 0.156 & 5 & 2 & .071 & 28 & 10 & 1 \\
\hline \multirow{2}{*}{$\begin{array}{l}\text { 7. causing bad } \\
\text { feelings/wave } 1\end{array}$} & & & & & & & & & & & & & & & & \\
\hline & 0.000 & 0.017 & 0.001 & 0.000 & 0.000 & 0.021 & & 0 & 0.032 & 0.829 & 0.476 & .069 & 0.003 & 0.050 & 168 & 974 \\
\hline \multirow{2}{*}{$\begin{array}{l}\text { 8. mocking } \\
\text { behaviour/wave } 1\end{array}$} & 0.544 & & 0 & 0. & & & 0 & 1.000 & & .077 & 0 & 0.033 & 0.197 & 153 & 126 & 0 \\
\hline & 0.000 & 0.000 & 00 & 00 & 01 & 0 & 0. & & & 7 & 1 & & 55 & 4 & 42 & 0.852 \\
\hline \multirow{2}{*}{$\begin{array}{l}\text { 9. insulting } \\
\text { behaviour/wave } 2\end{array}$} & & & & & & & & & & & & & & & & \\
\hline & 0 & 0 & 0.017 & 1 & 0.011 & 3 & 2 & 0 & & 0 & 0 & 0 & 00 & 0.000 & .000 & 0000 \\
\hline \multirow{2}{*}{$\begin{array}{l}\text { 10. underestimated } \\
\text { attitudes/wave } 2\end{array}$} & 0.083 & 0.197 & 0.007 & 0.018 & 6 & 2 & & 77 & $0.508^{* *}$ & 1.000 & & & & & & \\
\hline & (2) & - & & 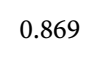 & & & & & & & & & & & 01 & \\
\hline \multirow{2}{*}{$\begin{array}{l}\text { 11. underestimating } \\
\text { intelligence/wave } 2\end{array}$} & ( & 0.183 & 0.159 & $34^{*}$ & & 0.165 & 77 & 0.069 & & & 1.000 & $3^{* *}$ & & & & \\
\hline & 0.015 & 0 & 0.140 & 28 & 0.007 & 0.125 & 0.476 & 1 & 0.000 & 0.000 & & 0.000 & 0.000 & 0.000 & 000 & 0.0 \\
\hline \multirow{2}{*}{$\begin{array}{l}\text { 12. ironic } \\
\text { comments/wave } 2\end{array}$} & & & & & & & & & & & & 0 & & & & \\
\hline & & & & & & & & & & & & & 0 & 0 & 0.001 & \\
\hline \multirow{2}{*}{$\begin{array}{l}\text { 13. rude } \\
\text { behaviour/wave } 2\end{array}$} & * & $0.246^{*}$ & $0.215^{*}$ & $18^{* *}$ & $0.264^{*}$ & 0.194 & $0.310^{* *}$ & 0.197 & $0.526^{* *}$ & 0. & & & 1.000 & $0.446^{* *}$ & & \\
\hline & 0.000 & 0.021 & 0.044 & 0.002 & 0.013 & 0.071 & 0.003 & 0.065 & 0.000 & 0.002 & 0.000 & 0.000 & & 0.000 & 0.003 & - \\
\hline \multirow{2}{*}{$\begin{array}{l}\text { 14. lessening } \\
\text { behaviour/wave } 2\end{array}$} & 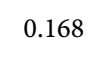 & & & & & & & 0 & 0 & & & & & 000 & & \\
\hline & 0.117 & & 0.223 & 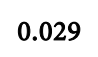 & 5 & 8 & 0 & 4 & 000 & 0.000 & 0.000 & 0.000 & 0.000 & • & 0.000 & 0.000 \\
\hline \multirow{2}{*}{$\begin{array}{l}\text { 15. causing bad } \\
\text { feelings/wave } 2\end{array}$} & $0.257^{*}$ & $0.278^{* *}$ & 0.135 & $0.349^{* *}$ & 0.204 & $0.273^{*}$ & 0.148 & 0.126 & $0.495^{* *}$ & $0.343^{* *}$ & $0.512^{* *}$ & $0.356^{* *}$ & $0.313^{* *}$ & $0.673^{* *}$ & 1.000 & $0.685^{* *}$ \\
\hline & 5 & 0. & 0 . & & 0 & & 8 & & 0 & 1 & 0 & 1 & 3 & 0.000 & & 0.000 \\
\hline \multirow{2}{*}{$\begin{array}{l}\text { 16. mocking } \\
\text { behaviour/wave } 2\end{array}$} & 1 & 0. & 0. & 4 & 6 & 31 & 4 & 20 & 0 & & & & & & & 1.000 \\
\hline & 0.049 & 0.114 & 0.664 & .087 & 0.174 & 0.091 & 0.974 & .852 & 0.000 & 0.000 & 0.000 & 0.000 & 0.000 & 0.000 & .000 & . \\
\hline
\end{tabular}

